\title{
Assessment of Mothers' Challenges, Support and Coping Strategies towards Caring for Preterm Babies Post-Discharge from Presbyterian Hospital in Bawku Municipality, Ghana.
}

\author{
Francis Abugri Akum* \\ PhD student, Texila American University/ Central University of Nicaragua, Ghana
}

*Corresponding Author: Francis Abugri Akum, PhD student, Texila American University/ Central University of Nicaragua, Ghana, Email:akumfrancis@gmail.com

\begin{abstract}
Background: Neonatal mortality has remained astronomically high globally and most of these deaths are from Sub-Saharan Africa (SSA). Preterm birth is associated with a higher risk of neonatal deaths and accounts for about $31 \%$ of neonatal deaths in Ghana. The objective of the study was to explore preterm babies care challenges and support in the Bawku Municipality of Ghana.
\end{abstract}

Methods: This study was an explorative descriptive study design using a qualitative approach to assess preterm babies care challenges and support at home after they were discharged from the Bawku Presbyterian hospital between May to December 2017. Data was collected through in-depth interviews, focus group discussions using guiding questions and direct observation with a checklist to triangulate findings from 21 mothers of preterm babies by enabling them to express the challenges they encountered, support given to them and the coping strategies adopted during the care of preterm babies in their various homes.

Results: All the study participants during IDIs and FGDs reported that caring for the preterm baby was very tedious and demanding. This affected them negatively on so many dimensions of their lives. The challeng es mentioned by the mothers were categorised into four major themes; physical, economical, socio-cultural and spiritual. All the 21 mothers said they one way or the other got some form of support from their husbands, inlaws, friends, extended family members and religious groups. Overwhelmed with the challenges they faced, the mothers adopted strategies that enabled them to cope with the care of their preterm babies and these were understanding the baby needs and having faith in God.

Conclusion: Regardless of the challenges encountered, they never relented in giving their maximum care the babies needed and really saw remarkable growth and development of their babies.

Keywords: Preterm babies; support; challenges; Bawku Municipality; coping strategies.

\section{BACKGROUND}

The 2030 Sustainable Development Goal (SDG) 3 target 3.2 - of reducing neonatal and under-5 mortalities to at least as low as 12 per 1,000 live births and 25 per 1,000 live births respectively by 2030 [1] will be a mirage without reducing newborn mortality rates. Reducing preterm deaths is very critical part of reducing neonatal mortality since prematurity and low birth weight are direct causes of $28 \%$ of global neonatal mortality [2].

About 15 million babies globally are born premature and more than one million of them die immediately after they are born [3]. About 99\% of these deaths occur in the low and middle-income countries due to complications.
These births are mostly from Sub-Saharan Africa (SSA) and South Asia due to lack of live supporting equipment in health facilities to care for them. Ghana ranked $14^{\text {th }}$ and $25^{\text {th }}$ for world preterm birth rates in 2010 and 2013 respectively and the number of deaths due to preterm birth complication were 7, 200 (31\% of neonatal deaths) in 2013 [4]. About threequarters of these babies could be saved if proven and less expensive management and prevention options are translated into practice [3].

Most preterm babies are delivered at home and if effectively managed at home, their chances of survival will be high. A study was done by [5], in India (rural Gadchiroli) showed that appropriate home-based management reduced 
the Case Fatality (CF) by nearly $60 \%$ for Low Birth Weight (LBW) and by nearly $70 \%$ for preterm neonates. Therefore if preterm babies can be effectively managed at home when mothers/caregivers are given the necessary information on how to care for their babies and also with frequent visits by health workers to give them the necessary support, case fatality will reduce. Therefore, the objective of this study was to explore the challenges encountered and the support received by mothers of preterm babies caring for their babies at home after discharge from the hospital.

The findings will help policymakers, stakeholders working around newborn health contribute to the improvement of quality of care for preterm babies to enhance their survival and therefore reduce neonatal mortality in the Bawku Municipality and other similar settings in Ghana.

\section{Methods}

\subsection{Study Location}

The study was done in Bawku Municipality in Ghana which is located approximately between latitudes $11^{\circ} 11^{\prime \prime}$ and 100 40" North and longitude $0^{\circ} 18^{\prime \prime} \mathrm{W}$ and $0^{\circ} 6^{\prime \prime} \mathrm{E}$ in the northeastern corner of the region. It shares boundaries with Pusiga District to the North, Binduri District to the South, Garu -Tempane District to the East and Bawku West District to the West and has a total land area of 247.23720 sq.km [6].

\subsection{Study Design}

This study was a descriptive study design using a qualitative approach to assess preterm babies care challenges and support at home after they were discharged from the hospital. Mothers of preterm babies who delivered in the Bawku Presbyterian hospital within the study period and consented to participate in the research study were recruited for the study.

\subsection{Data Collection Technique}

Data was collected through in-depth interviews using guiding questions, focus group discussions and direct observation with a checklist to triangulate findings from mothers of preterm babies by enabling them to express how preterm babies are cared, the challenges encountered and the support given to them in their various homes. The in-depth questions were open-ended and exploratory enough to get detail information. Probing questions were asked to push participants to bring out the required information which they may forget to include in their initial discussions. The study took place between May and December 2017. The interviewers took notes and also tape recorded the interviews with the permission of the respondents. The interviewers' notes and audio recordings were transcribed and translated into English for those participants who could only understand the local dialect.

\subsection{Data Analysis}

The data was analysed using content analysis according to appropriate themes and subthemes captured during the interview. The data collected was checked for completeness and directed approach to content analysis was used to analyse the data with the help of themes deriving from prior research findings to categorise key concepts or variables and these were coded. Other texts that did not fit into the initial coding scheme were given new codes for significant findings made.

\subsection{Inclusion and Exclusion Criteria}

Study Participants included all mothers of preterm babies born before the gestation period of 37 weeks within the study period from May to December 2017 and were willing to participate. Mothers of preterm babies who died were not included in the study as well as those mothers who did not consent to participate in the study.

\subsection{Ethical Clearance}

Permission for this study was sought from the community chiefs and elders, Municipal health directorate and municipal Assembly. The participants were given written/verbal consent prior to their participation. The research team members explained the purpose of the studies to all the study participants and enrollment into the study was purely voluntary. Participants were given the liberty to cease participation at any time without any penalties. Consent was also sought from study participants to use tape recorders.

\section{Results}

All the study participants during IDIs and FGDs reported that caring for the preterm baby was very tedious and demanding requiring 24/7 care. This they said affected them negatively on so many dimensions of their lives. They, however said they never relented in giving them the 
maximum care the babies needed and really saw their remarkable growth and development.

\subsection{Challenges}

The challenges mentioned during the IDIs and FGD by the mothers were categorised into four major themes; physical, economical, sociocultural and spiritual.

\subsubsection{Physical challenges}

The physical challenges sub-categorised included mother exhaustion, baby feeding difficulties, slow baby weight gain and caring for other siblings. The mothers said caring for a preterm baby is physically exhausting and even affects their physical appearance (not able to dress well).

A multiparous mother of a preterm baby who gave birth to a preterm baby after giving birth to five children mentioned that she has so much weight and really upon observation she looking frail with sleepless facial expression narrated at length about her ordeal as a preterm mother:

"Caring for a preterm baby is a hell and since then it has been like I am really dreaming of this suffering but not a reality. I don't know why God has given me a preterm baby. The baby is fed all times day and night, you have to as well do the house chores at the same time, and this is physically exhausting. There is no help coming from anywhere. My husband doesn't and my mother-in-law who is supposed to help especially bathing the baby is also not doing that. I have lost weight up to $8 \mathrm{~kg}$ from the day this baby came out till date. Sometimes no appetite for food even when hungry, the suffering is too much".

IDI, multiparous mother of a preterm baby. Another mother said they have been calling her a "dirty woman" since she is not able to bath neither brush her teeth at times because she to always meet her baby needs.

"I have to stop bathing or brushing my teeth when I hear the cry of my baby. Personal hygiene is a problem. Even the make-up I used to do and dress well is all in vain and is like I am now in a new world with a lot of experiences".

IDI, Mother of a pre te rm baby.

\subsubsection{Economic/Financial}

The economic cost of caring for a preterm neonate was a major challenge to the mothers despite that they were previously one or the other involved in income-generating activities.
All the mothers said it was costly and expensive caring for a preterm baby which affected them economically due to the continuous care and no time to do their business or farming to get income. The said, they stopped whatever jobs they were doing to earn income and all the burden of financial issues was left unto their husbands. They said the frequent travel to and back from the hospital weekly or fortnightly for reviews was a financial burden to them due to the cost of transportation. Another high cost incurred was buying SMA (baby feed) to supplement their breast milk. One of the mothers during one of the FGDs with the preterm mothers had this to say:

"My small provisions shop has collapsed to zero because I have to stop selling and look after my baby at home. Eih! It is very expensive, it is costly caring for a preterm baby. I need to always pay and join trotro (bus) or sometimes 'Okada' (tricycle) to and back from the hospital, buy SMA (babyfeed) because my breast milk is not enough and this all money".

\section{FGD, mother of a preterm baby.}

One of the mothers too complained:

"Hmmmm! Very expensive and there are times you just don'thave money at all or it is not yet ready to attend the hospital for review. Even sometimes to get 'key soap' to wash the baby clothes and that of the family is a big problem. I use to help in a chop bar to wash dishes and at the end of the day I am paid and that was keeping the house but now this not possible. Now, I am not able to go out left alone to work for daily bread. Even the daily feeding fee I have been giving to my two children to pay at school for their lunch is now a major problem. Their father is not working and I was struggling with the dishwashing to pay but, now that I cannot work again it is a big problem. My brother sometimes now support them".

\section{IDI, mother of a prete rm baby.}

One of the mothers who is a nonprofessional teacher teaching in a private school had to resign from her job because she exhausted her maternity leave and proprietor refused to give her additional days to take care of her baby at home narrated her ordeal:

"Right now I am confused and it is not really easy at all for me. I was a non-professional teacher teaching in a private school and now out of the job because my proprietor wouldn't 
add me more days after I exhausted my maternity leave of 3 months to be able to take of my baby. Even getting the 3 months maternity leave was even a tussle because the private businesses are only interested in their money and not the welfare of their staff, so, I had to quit the job. My baby is more precious to me and by God's grace, I will survive despite the financial difficulties. I currently rely on my husband who is a tailor and it is also not easy for him to provide what we need. My aunty daughter is staying with me here and she has to sell ice water after school for to augment my husband income in order to survive. My baby's SMA feed got finished about 3 days as I am talking to you, I haven't gotten a penny yet to buy and breast milk is also not enough. The baby sucks all times and no much breast milk comes out. It is a real headache paaa!"

\section{IDI, mother of a pre te rm baby.}

\subsubsection{Socio-cultural Challenges}

Another very pathetic and worrying aspect of the challenges pertaining to caring for a preterm baby as reported by the mother were those challenges classified under socio-cultural. Socio-cultural practices are very important in Ghana especially among people living in northern Ghana and anything that is an obstacle to such practices is a serious challenge.

All the 21 mothers during IDIs said they never lived dignified and meaningful social lives after they gave birth to their premature babies. The women reported that, are not able to mix and socialize with others as they use to do and now isolated. They said are not able to attend social gatherings like outdooring, funerals, birthdays, festivals and the like because they had been at home always to take care of their babies. They said sacrificed all these social activities in order to take care of their babies. All the Muslims mothers narrated that, they could not perform the usual 'Suuna' (Islamic baby naming ceremony) which is supposed to be done on the $7^{\text {th }}$ day of the baby's delivery due to the small nature of their babies and some babies were even still hospitalized in the hospital within the $7^{\text {th }}$ day of delivery. A Muslim mother who could perform the 'suuna' of her preterm baby had this to say:

"I was ashamed when the 'suuna' of my baby never performed on the $7^{\text {th }}$ day of her delivery. Really a shame. People were asking why it was never performed but I was feeling ashamed and guilty to tell them that I delivered a premature baby. You know the "suuna' day is always a day that you have dress expensively in white to show the proudness of being a mother but that never happened. It appeared to me I was a social outcast when my friends, family members, and co-workers were calling to find out why the 'suuna' was not done on the $7^{\text {th }}$ day. I really, really didn't know what to tell them. It was a very difficult situation I found myself".

IDI, a Muslim mother of a pre term baby. A frustrated mother who gave birth to premature twins narrated:

"It appeared I am now in a different world, I used to attend funerals, birthdays, weddings, festivals and now this is no more. I cannot attend these events to socialize because I have to be at home to take care of my babies. They are too tiny to carry along to such events. These babies are so tiny to carry along, unlike term babies. Everyone will always go out during the day living me alone at home and there is no one to talk to. It is just I now found myself in different a world. Loneliness is our problem".

IDI, mother of preterm twins.

During the FGD with the women, majority of them agreed that their husbands do not help much in caring/handling their babies. Most of them said, culturally because they have given birth to preterm babies, they have to bath some concoctions for four months before they can have sex with their husbands. Some of them complained that because they have to wait for some time before having sex, their husbands started having extra-marital sexual relationships with women and it is quite disturbing to their marriages. Below is a quote that buttresses how the presence of a preterm baby being a recipe for the men to have an extra-marital sexual relationship:

"Giving birth to a preterm baby within the Kusasi tribe has a cultural connotation and my husband has to cease having sex with me until I bath some local medicine concoctions for four months. I have seen that of late, my husband has started having sex with women outside our marriage and this is quite disturbing. It is not my fault that I gave birth to this preterm baby. Can you see all this that I am going through? Why and can 't he also wait for the four months? I am devastated and no woman can take this".

FGD, mother of a preterm baby. 


\subsubsection{Spiritual Challenge}

Worshipping God is very important to the African and anything that is an obstacle to performing such function is seen as an impediment to their faith. During the IDIs, all the mothers who are either Christians or Muslims reported that having to care for their preterm babies affected them negatively as far as worshipping God is concerned. They said, they could not go to the mosque on Fridays or to church on Sundays to pray since it is difficult and also shameful to carry such tiny babies to such gatherings. A mother said, she is not able to even perform all the usual five times daily prayers since she gave birth to her preterm baby. A Muslim mother narrated her traumatizing ordeal:

"Since I gave birth to my preterm baby, it is now like I am not in touch with Allah. I am not able to perform all the usual five times prayers a day left to talk of even going to the mosque on Fridays. Spiritually I am weak and this is against Allah. I don't know what to do and my babies will not allow me to pray. May Allah forgive me and see me through these trial times".

\section{IDI, a Muslim mother of a pre te rm baby.}

Another Christian mother also reported that, having a preterm baby derailed her relationship with her God. She said as a charismatic member of the Catholic Church, she needed to be going for worship every Tuesdays and Saturdays to fortify herself spiritually but could attend those worships because of her preterm baby.

"I am spiritually backwards now because I no longer fellowship with my fellow charismatic members on Tuesdays and Saturdays for spiritual fortification. I am really weak spiritually and this has affected me so much. I know my current predicament of things not going on well in the family is as a result of this lapse. Hardship, sickness and so many calamities in the family now. I used to pray and send the Holy Ghost fire to torment the evil ones but now, this not effective. Anyway, it shall be well. I still thank the good Lord for everything"

\section{IDI, a Christian mother of a preterm baby.}

\subsection{Support}

All the 21 mothers said they one way or the other got some form of support from their husbands, in-laws, friends, extended family members and religious groups. The care for such babies really needs support from all facets that will give them the encouragement and morale to enable them to take care of their babies at home.

\subsubsection{Support received from Husband}

Among the 21 mothers interviewed, only two said they did not receive support from their husbands. One of those mothers who did not get support from her husband and a Muslim by religious faith said, her husband has two other wives and that might be the reason why she has not gotten support from him. The other one who did not also get support said. Her husband is residing in Kumasi (one of the cities in Ghana) and since from the day she delivered till now, he never visited home. Those who received support from their husbands was in the form of financial, helping to care for their babies, taking care of other siblings to enable the mothers to concentrate on caring for the preterm babies at home.

Those mothers who had support from their husbands had these to say:

"Since I gave birth to my preterm baby, my husband has been so supportive. He comes from the farm early, helps bath the other children and will handle my preterm baby for me to do the house chores and cook for the family. He also supports financially for the upkeep of the family. In our traditional home, I am supposed to serve him his food, but he has defied all those old fashion traditions and serves himself. He is really supportive".

IDI, mother of a preterm baby. "I was devastated I got home after discharge from the hospital, thinking of how I can care for my baby. All the time I was weeping but husband was the consoler. He was able to counsel me and helped me so much in caring for the baby. He gave me the assurance of his support and told me whatever has given, He has a reason to and the tiny baby is equally a baby and will survive. He really supported me physically, spiritually, financially and psychologically. He has been my motivator. Even, there were times my baby will have breathlessness, but I will ask that we pray and commit him to the lord hands and was like a miracle".

\section{IDI, mother of a preterm baby.}

One of the mothers who never got support because her husband was in Kumasi and never visited home since she delivered her preterm baby had this to say: 
"Since I gave birth and I told my husband on phone on the nature of the baby, she never visited home left alone to support. I have been on the mercies of friends for help and that where I have found myself now. Even calling to find out how we are faring considering the kind of baby I have delivered is not even there but I am managing and Goodwill see me through, though it is very difficult for me".

\section{IDI, mother of a prete rm baby.}

The Muslim mother who said because the husband has other two wives and therefore not supporting her also narrated her part:

"You know in a polygamous family, the man is always very careful and the not mess by seen to be supporting one wife more than the others. I understood him but my situation is different. He should have supported me because I am caring for a preterm baby and not able to go out and trade to get income. Even my rivals are very helpful, there sometimes help me wash, sweep the compound and even fetch waterfor me while I take care of my baby. I don't know why he will not also see my situation differently, my rivals are aware that this is a very rare situation".

\section{IDI, mother of a preterm baby.}

\subsubsection{Mother-in-laws Support}

The majority of the mothers said they received some form of support from their mother-in-laws except three who reported that they never received support from their mother-in-laws. Those who received support mentioned some of the support to include helping in house chores, fetching water, washing the babies' clothes, bathing the babies and cooking for the family. This was buttressed by the following statement:

"My mother-in-law has been very wonderful with her support in taking care of my baby. She has helped me in doing most of the house chores, fetching water, washing my baby clothes and bathing the baby twice daily. I must praise her for this wonderful support. Even, if she hears the baby cry at night, she knocks my door to find out what is wrong. She is more of my biological mother than just a mother-in-law. May God continue to give her more strength and long life".

\section{IDI, mother of a preterm baby.}

A mother who got immense support from her mother-in-law has this:
"My mother-in-law moved to us and staying us since my baby was discharged from the hospital. She is currently staying with us and doing almost everything for my baby. From bathing, washing, cooking to the handling of the baby if I have to also do other things. I think her presence is really a relief to me. I didn't know where to turn to for support. She is very caring. This is God's intervention".

\section{IDI, mother of a preterm baby.}

One of the two mothers who never got support said her mother-in-law lives in a different region of Ghana and when she first gave birth to a term baby during first pregnancy, the mother-in-law visited them the third day with so many things as a gift. She however said, when she gave birth to the preterm baby and her husband informed her through a phone call, the mother-in-law never step foot to visit them but rather said, she doubts the survival of the baby.

"Hmmmm! My situation is a pity since a gave birth and discharged from the hospital, my mother-in-law never stepped foot here though she was told that I gave birth to a preterm baby. She visited and even stayed with us for some time during my first delivery when the baby was a term one. But in this case, she didn't come and even made a comment to my husband that, she doubt if the baby will even survive. What kind of mother-in-law is this? If you cannot support us, then you encourage us".

\section{IDI, mother of a preterm baby.}

\subsubsection{Support from extended family}

All the twenty-one mothers who participated in the study said they received support from their extended family members when they gave birth to their preterm babies. Some of these mothers received physical, psychological and financial support, while others got only physical support from their extended family members. The support they received enabled them built the courage and confidence to care for their babies.

One of the mothers who received both physical and financial support from her brother and cousin narrated her joy:

"My elder brother has been supportive when I delivered, he sent me money enough for our upkeep and bought warm clothing, wipers, diapers, and baby feedsfor me. He has been so nice to me. When his driver is sending his children to school, he passes by to pick my daughter to school as well. There is no day he 
will not call me to find out how the baby is doing. I really appreciate him as a brother. As for my cousin Laadi, since I gave birth to this my preterm baby, she has been with me from the hospital up till today. She does virtually everything for me in the house. I think I am surrounded by a very good and lovely family members. I am blessed".

\section{IDI, mother of a preterm baby.}

The mothers who said they got psychological and financial support stated the following:

"My aunt has been so supportive. She used herself as an example to console me. She advised me not to be so worried about the survival of my preterm baby because her firstborn was also a preterm baby who weighed $1.7 \mathrm{~kg}$ and the baby survived whereas mine baby weighed $1.9 \mathrm{~kg}$. She said my baby will survive and therefore I should not be having tears flowing every night. My aunty further said it is preterm baby boys who usually do not survive and that once mine is a girl, she high chances of surviving. She gave me immense support".

IDI, mothe r of a pre te rm baby. Another mother has this to say during IDI:

"My younger sister works with the bank and has been supporting me with money and my baby things. She told me to feel free to always tell her what I am lacking and she will provide. As Rahi, she is always ready to support me in any form except that she has no time to come down and help me in caring for the baby because of the nature of her work. I appreciate her so much. Allah will give her the energy and long life"

\section{IDI, mother of a preterm baby.}

\subsubsection{Support from friends}

Majority of the mothers interviewed received some form of support from their friends in the form of money and material gifts. However some mothers never received support because they declined from the visit of their friends as a way of infection prevention. These support immensely helped the mothers to take care of their preterm babies. Another reason given by some of the mothers who declined to their friends visits also said their babies were too tiny and feel shy of their friends visiting them.

A mother who received material and financial support from her friends narrated:

"When my friends heard that I gave birth they started trouping to visit and gave me so many gifts. Though we were cautioned not allow visitors due to transmission of germs to the babies, I couldn't prevent them. They are my good friends and very caring. Some of them sometimes even stay with me for some hours to help do washing and house chores. They are lovely friends and that is why the old adage says 'a friend in need is a friend indeed'. So so very lovely friends".

\section{IDI, mother of a preterm baby.}

A mother who never received support friends because it was a measure to prevent her baby from infections also had this to say:

"I never allowed any friend to visit because I was afraid that my baby will acquire infections from them once we were educated by the midwives to prevent visitors coming into contact with our babies to prevent infection. I had to observe this advice as such. My baby to is tiny and think preventing them from visiting will outweigh the suppose gift that they may bring. I cannot afford to lose my baby, I want my baby to survive".

\section{IDI, mother of a preterm baby.}

\subsubsection{Support from the religious}

During the IDIs, some of the mothers said they got some form of support from the religious. Some of the support mentioned included prayers, financial and psychological. Majority of these mothers were Christians and few Muslims. Some of these mothers who got support from the religious had these narrations:

"My reverend father paid me a visit twice and prayed for my baby and I. He also counselled me not to be disturbed about my current predicament and that with God everything is under control. I was also presented with money and some fruits. I was really happy to see my priest coming to visit. The Catholic church is really doing well".

\section{IDI, mother of a pre te rm baby.}

"My pastor and section of the church choir came to the house the third day my baby was discharged from the hospital. They offered my baby and I prayers and also donated baby warm clothes, diapers, wipers and SMA (baby formula). I felt also felt belonged to a church and very much happy. You know this is a recognition of the role I play in the church as chorister. I was really very much gladdened".

IDI, mother of a preterm baby. 
'Our community 'Mallam' heard of my preterm baby and visited us at home. He made 'adua' (special prayerfor my baby and the family. He assured us of the survival of my baby and said he will continue to make 'adua' daily for the baby and the family. He gave me some money to support us care for the baby. He is a nice man and very encouraging".

\subsection{Coping Strategies by Mothers}

IDI, mother of a pre term baby.

Confronted with overwhelming physical and emotional task of caring for their premature babies, the need to adopt coping strategies is paramount to enable the mother care for their babies at home after discharge from the hospital. The mothers during IDIs mentioned two broad categories of strategies adopted to enable them cope with the care of their preterm babies. These were; understanding the baby needs and having faith in God.

\subsubsection{Understanding the baby's needs}

The mothers said during the care of their preterm babies, they had to observe to know and understand the needs of the babies. The mothers understanding of their babies behaviours that require action such as hunger, wet diapers, or seeking attention can help them to cope with caring for them. A mother who was able to recognise the needs of her preterm baby that helped her coped with caring for him narrated:

"When I was first discharged from the hospital to go home and continue with care of my baby, it was very difficult to understand her. She was always crying but when I observed and understood her needs like when she cries it could be that she is hungry, diapers are wet or wants to be picked. I was then able to meet her needs, this made me cope up with caring for her. When she cries, I know what might have gone wrong with her and quickly administer the right intervention. It has helped me so much"

\section{IDI, mother of a pre te rm baby.}

\subsubsection{Using religious belief}

All the mothers said they trust in God and whatever the Lord gives them, they have to be pleased with and that, the same God will give you the strength and heart to take care the babies. Religious belief is very strong in Africa for that Ghana whenever something good or bad is encountered by an individual, group or even a community. One of a Muslim mother of a preterm baby had this belief to say:
"Allah is the most highest and has plans for everyone. Allah has given me the strength to accept my baby and being able to meet his needs. I am very grateful and content"

\section{IDI, a Muslim mother of preterm baby.}

During FGDs the mothers mentioned that prayers help a lot during very difficult situations and that daily prayers helped them so much to get the strength and resources to cater for their babies. During one of the FGDs, the mothers narrated;

"Prayer is a major weapon during very difficult times. With prayers, we have overcome the difficult situation we found ourselves. Our pastors, Liman's and Rev. Fathers have been praying for us as well and this has brought us this far with our babies. You know everything about a preterm baby is so disheartening. We find it difficult to also go out with them due to stigma and caring for them is time demanding. We will continue to pray for the strength and wisdom to enable us take care of our babies".

FGD, mothers of preterm babies.

\section{DIS CUSSIONS}

\subsection{Challenges of Caring for Preterm Ne wborns at Home}

The findings indicated that caring for a preterm baby was very tedious, demanding and challenging requiring $24 / 7$ care as reported by the mothers. The study identified numerous challenges faced by mothers with the home management of preterm babies. Among the challenges mentioned by the mothers were general physical, Economic/Financial, Sociocultural and spiritual. Some of the general physical challenges as indicated by the mothers were; maternal exhaustion, baby feeding difficulties, slow baby weight gain and caring for other siblings. The mothers said caring for a preterm baby is physically exhausting and even affects their physical appearance (not able to dress well). Similar findings were also found in a study done in rural Mangochi, Malawi [7] involving mothers, fathers, grandmothers and traditional healers as study participants also reported that caring for preterm newborn was demanding, requiring mothers to be with their babies all the time and this affects their business, farming and household chores.

Aside from the extra expenditure required to take care of their preterm babies, the mothers also indicated that they used to do others 
businesses like petty trading and farming to generate income to support the family but they had to stop these economic ventures in order to take care of their preterm babies. It is also a common practice in Ghana that pregnant mothers carry out economic activities to generate and save money during their few months to delivery as a way of preparing towards the delivery of their newborn babies. But mothers unexpectedly delivering preterm affects the financial preparations towards the care of their babies and families.

The study further indicated that the mothers also encountered socio-cultural challenges pertaining to caring for their preterm babies. Socio-cultural practices are very important in Ghana especially among people living in northern Ghana and anything that is an obstacle to such practices is a serious challenge. The mothers could not attend social gatherings like outdooring, funerals, birthdays, festivals and the like because they had to be at home always to take care of their babies. They sacrificed all these social activities in order to take care of their babies. All the Muslims mothers narrated that, they could not perform the usual 'Suuna' (Islamic baby naming ceremony) which is supposed to be done on the $7^{\text {th }}$ day of the baby's delivery due to the small nature of their babies and some babies were even still hospitalized in the hospital within the $7^{\text {th }}$ day of delivery. In Ghana, it is a taboo to perform a naming ceremony of a preterm baby on the $8^{\text {th }}$ day of delivery as the culture demands [8]. However, the babies were given names through ceremonies after some months when the babies grew and put on weight.

The study findings also indicated that religious challenge was also a concern by the mothers of the preterm babies. Worshipping God is very important to the African and anything that is an obstacle to performing such function is seen as an impediment to their faith. All the mothers whether Christians or Muslims indicated reported that having to care for their preterm babies affected them negatively as far as worshipping God is concerned. They said they could not go to the mosque on Fridays, neither to the church on Sundays to pray since it is difficult and also shameful to carry such tiny babies to such gatherings. Findings of a study conducted in Accra, Ghana [9] corroborate the findings of the current study. The study by Suraju showed that mothers with preterm babies could not also attend social and religious gatherings like church services.

\subsection{Support}

The findings indicated that all the 21 mothers said they one way or the other got some form of support from either their husbands, Grandmothers, in-laws, friends, extended family members or religious groups. The care for such babies really needs support from all facets that will give them the encouragement and morale to enable them take care of their babies at home. Mother-in-laws are the source of support when it comes to caring newborns in Ghana but three (3) of the mothers indicated that they had no support from their mother-in-laws. The revelation in this study is quite worrying because it may suggest the beginning of a breakdown of Ghanaian support system due to modernity.

A similar study was done in Iran however also indicated that emotional supports from husbands, friends and relatives is a good strategy to build confidence in the mothers and reduces stress to enable them care for their preterm newborns [10]. Similarly, [11] indicated that mothers sought for different sources of support to enable them to cope with their stress and concerns about the health of their premature newborns, appearance, survival and the chances of losing their motherhood roles. Also, a study done by [12] revealed that providing support enhances mothers' confidence and reduces their emotional reactions and that they expected support from their husbands and mothers especially during days after delivery. The findings of this study are in conformity with a study done in Australia looking at stress and coping in fathers following the birth of a preterm infant which indicated that fathers used accommodation as coping strategies and made efforts to change situations that seemed stressful [13]. According to their study, partners were the major source of emotional support and the provision of information by nurses and doctors was also supportive them.

\subsection{Coping Strategies by Mothers}

Despite the overwhelming challenges encountered by the mothers caring for their preterm babies at home after discharge from the hospital, they developed certain coping strategies to deal with these problems and difficulties as they cared for their babies. "Coping is the effort to control, reduce or learn to tolerate the threats that lead to stress" [14]. The mothers in this study mentioned two broad categories of strategies adopted that enabled 
them coped with the care of their preterm babies. These were; understanding the babies' needs and having faith in God. On the understanding of the babies' needs, the mothers identified specific needs that made the babies' comfortable and prevented them from unnecessary cry. The mothers observed and understood their babies' behaviours that require action to prevent them from crying such as hunger, wet diapers, or seeking attention. According to [9], the mothers indicated that they were able to identify the exact needs of their preterm babies that enable them address those needs to make them comfortable to avoid crying unnecessarily.

On the part of mothers relying on God as their source of strength due to their religious faith, they indicated that they had trust in God and whatever God gives, you have to be pleased with and that, the same God will give you the strength and heart to take care. A study was done in Iran also reported similar findings such as mothers trusting in God's immortal power in dealing with the problems and difficulties of the situation they encountered and asked God's help [10]. The findings of [15] also indicated that some mothers went to church and prayed when they were extremely worried about their infant condition in NICU. In many parts of the world and especially in Africa people become religious when they encounter hard times or when ill $[16,17]$. In Africa it is believed that life is associated with religious beliefs and practices and religious beliefs being described as statements to which members of a particular religious body adhere to [18]. It is worth noting that religion performs certain primary social and psychological functions like supporting people to cope with challenges they are confronted and integrating into the society.

Organising mothers of preterm babies into groups to learn from each other and also encourage one another is very supportive in coping with stress. They can learn skills from one another regarding how to care for their preterm babies. Peer support is much appreciated since they know that others too are having similar situations.

\section{CONCLUSiON}

The findings of the study highlighted that mothers who have delivered preterm babies have numerous challenges caring for their babies at home. The challenges are diverse and enormous and ranging from the care of the newborn to support the mothers require from family members, friends and the religious to enable them cope. The mothers adopted strategies that enabled them to cope with the care of their preterm babies and these were understanding the baby needs and having faith in God.

Understanding the mothers' challenges and how the cope with the care of their preterm babies is important in order to provide appropriate, responsive and proactive services to support and improve that experience. Regardless of the challenges encountered, they never relented in giving their maximum care the babies needed and really saw remarkable growth and development of their babies.

\section{REFERENCES}

[1] United Nations, Department of Economic and Social Affairs, Population Division. (2015). World Population Prospects: The 2015 Revision.

[2] Lawn, J.E., Osrin, D., Adler, A. \& Cousens, S. (2008). Four million neonatal deaths: counting and attribution of cause of death. Paediatric and Perinatal Epidemiology 22, 410-416.

[3] World Health Organisation. (2014). World Health Assembly closes News release, Geneva. Retrieved June 11, 2016 from http:// www.who.int/mediacentre/news/releases/2014/ WHA-20140524/en/?\&session id=f35af0e4d 2aff508277b fdb7514be 5bc

[4] Mamaye (2014). Factsheet on preterm birth in Ghana, Ghana.

[5] Bang, A.T., Baitule, S.B., Reddy, H.M., Deshmukh, M.D. \& Bang, R.A. (2005). Reduced incidence of neonatal morbidities: effect of home-based neonatal care in rural Gadchiroli, India. Journal of Perinatology 25 (Suppl 1), S51-S61.

[6] Ghana Statistical Service. (2014). 2010 population census, district analytic report of Bawku Municipality. Accra Ghana.

[7] Gondwe, A., Munthali, A.C., Ashorn, P. and Ashorn, U. (2014). Perceptions and experiences of community members on caring for preterm newborns in rural Mangochi, Malawi: a qualitative study. BMC Pregnancy Childbirth; Dec 2; 14(1):399

[8] Nukunya, G. K. (2003). Tradition and change. An Introduction to sociology. Ghana Universities Press.

[9] Suraju, A.H. (2013). The Experiences of Mothers Caring for Preterm Babies at Home: A Study in the Accra Metropolis. Thesis (MPhil)University of Ghana. Retrieved May 20, 2015 from http://197.255.68.203/handle/123456789/ 5202 
[10] Arzani, A., Valizadeh, L., Zamanzadeh, V. \& Mohammadi, E. (2015). Mothers' strategies in handling the prematurely born infant: a qualitative study. Journal of Caring Sciences; 4(1), 13-24. doi:10.5681/jcs.2015.002

[11] Holditch-Davis, D. and Miles, M.S. (2000). Mothers' stories about their experiences in the neonatal intensive care unit. Neonatal Netw; 19 (3): 13-21.

[12] Barclay, L., Everitt, L., Rogan, F., Schmied, V., Wyllie, A. (1997). Becoming a mother-an analysis of woman's experience of early motherhood. Journal of Advanced Nursing; 25 (4): 719-28.

[13] Sloan, K., Rowe, J., \& Jones, L. (2008). Stress and coping in fathers following the birth of a preterm infant. Journal of Neonatal Nursing, 14, 108-115.

[14] Feldman, R. S. (1994). Essentials of understanding psychology. ( $2^{\text {nd }}$ ed.). McGrawHill Inc, North America.
[15] Schenk, L.K and Kelley, J.H. (2010). Mothering an Extremely Low Birth-Weight Infant: A Phenomenological Study. Advances in Neonatal Care, 10 (2), 88 - 97. doi: 10.1097/ANC.0b 013e3181d28330

[16] Hill, P. C., \& Pargament, K. I. (2003). Advances in the conceptualization and measurement of religion and spirituality: Implications for physical and mental health research. American Psychological Association, 58 (1), 64-74.

[17] Cummings, J. P., \& Pargament, K. I. (2010). Medicine for the spirit: Religious coping in individuals with medical conditions. Religions, 1, 28-53. Retrieved May 28, 2017 from www.mdpi.com/journal/religions

[18] Assimeng, M. (2006). Understanding society. An Introduction to Sociology for Africa Students Accra. Woeli Publication Services.

Citation: Francis Abugri Akum, Assessment of Mothers' Challenges, Support and Coping Strategies towards Caring for Preterm Babies Post-Discharge from Presbyterian Hospital in Bawku Municipality, Ghana. ARC Journal of Pediatrics. 2018; 4(1): 14-24. doi:dx.doi.org/10.20431/2455-5711.0401003.

Copyright: (C) 2018 Authors. This is an open-access article distributed under the terms of the Creative Commons Attribution License, which permits unrestricted use, distribution, and reproduction in any medium, provided the original author and source are credited. 